Article

\title{
Probing the Catalytic Activity of Tin-Platinum Decorated Graphene; Liquid Phase Oxidation of Cyclohexane
}

\author{
Mohammad Sadiq ${ }^{1, *}$, Saima Sadiq ${ }^{1}$, Muhammad Abid Zia ${ }^{2}$, Muhammad Ali ${ }^{1}$, Khalid Saeed ${ }^{1}$, \\ Muhammad Sohail Ahmad ${ }^{1}$ and Rahmat Ali $^{3}$ \\ 1 Department of chemistry, University of Malakand, 18800 Chakdara, Pakistan; \\ saimasadiq1978@yahoo.com (S.S.); muhammadali041988@yahoo.com (M.A.); \\ khalidkhali12002@yahoo.com (K.S.); sohail850@gmail.com (M.S.A.) \\ 2 Department of Chemistry, University of Education, Attock Campus, 43600 Attock, Pakistan; \\ abid@ue.edu.pk.com \\ 3 National Center of Excellence in Physical Chemistry, University of Peshawar, 25120 Peshawar, Pakistan; \\ rahmat_chemistpk@yahoo.com \\ * Correspondence: sadiq@uom.edu.pk; Tel.: +92-945-763-441
}

Academic Editor: Vijay Kumar Thakur

Received: 13 January 2016; Accepted: 5 February 2016; Published: 10 March 2016

\begin{abstract}
Pt-Sn supported on reduced graphene oxide (Pt-Sn/rGO) was synthesized and characterized by SEM, EDX, and XRD. The catalytic activity of Pt-Sn/rGO was tested for the solvent free liquid phase oxidation of cyclohexane to a mixture of cyclohexanol and cyclohexanone, also called KA oil, under mild reaction conditions. The products were analyzed gravimetrically, by UV spectrophotometer, and GC equipped with FID. The catalyst was found to be fairly active as well as selective for the desired products. The experimental data was analyzed by Freundlich, Temkin, and Langmuir adsorption isotherms. The L-H model was found to give a better fit of the data. The catalyst was fully recyclable and truly heterogeneous.
\end{abstract}

Keywords: Pt-Sn/rGO; cyclohexane; KA oil; L-H model

\section{Introduction}

The catalytic oxidation of cyclohexane to KA oil (KA oil: cyclohexanol and cyclohexanone) is of immense significance as it has a broad range of industrial applications [1]. It is used in the synthesis of Nylon-6, Nylon-66 and also used as an excellent solvent for coating processes [2]. These products are not only important intermediates in the manufacturing of many drugs, vitamins, and fragrances [3], but are also important as precursors in the synthesis of plasticizers and food additives as well [4]. Other uses of cyclohexanone include their use as starting materials in the synthesis of insecticides, herbicides, and pharmaceuticals [5]. The modern industrial process for oxidation of cyclohexane to a mixture of cyclohexanol and cyclohexanone relies on a cobalt salt as a catalyst, a temperature range of $150{ }^{\circ} \mathrm{C}-160{ }^{\circ} \mathrm{C}$, and pressure of air around about 1 atm under homogeneous reaction condition that results in the conversion of less than $6 \%$ and selectivity of cyclohexanol and cyclohexanone of around $80 \%$ [1]. Since, the process is characterized by low \% conversion, high operational cost, and a tedious recovery of the catalyst from the reaction mixture, researchers have been exploring various alternatives to overcome these drawbacks. The addition of other homogeneous catalysts have also been reported for the oxidation of cyclohexane, like transition metal salts containing $\mathrm{Co}^{2+}, \mathrm{Cr}^{2+} \mathrm{or} \mathrm{Mn}^{2+}$, metalloporphyrins, $\mathrm{MoO}_{3}, \mathrm{WO}_{3}$, and $\mathrm{Cr}_{2} \mathrm{O}_{3}$ [6,7]. When this process is carried out in the presence of anhydrous metaboric acid, $87 \%-90 \%$ selectivity of mixture of cyclohexanol and cyclohexanone at $10 \%-15 \%$ conversion could be achieved [8]. 
Besides homogenous catalysts, scientists have also tried various heterogeneous catalysts for the selective oxidation of cyclohexane to KA oil. Schuchardt et al. $[9,10]$ have reported improved results for the oxidation of cyclohexane using various metals and metals oxides supported on $\mathrm{SiO}_{2}$ as catalyst, however, leaching of metal was detected. Zhou et al. [11] investigated the catalytic oxidation of cyclohexane with $\mathrm{O}_{2}$ in the presence of nano crystalline $\mathrm{Co}_{3} \mathrm{O}_{4}$ catalyst using tert-butyl hydroperoxide as initiator, achieving $7.6 \mathrm{~mol} \%$ conversions and $89.1 \%$ selectivity at $393 \mathrm{~K}$ in $6 \mathrm{~h}$. However, in this process, without tert-butyl hydroperoxide (as initiator) the conversion was very low. Gold nanoparticles embedded in amorphous silica have shown a high catalytic activity and selectivity at $150{ }^{\circ} \mathrm{C}$ and $14.8 \mathrm{~atm} \mathrm{O}_{2}$ for $3 \mathrm{~h}$. However, this system also required tert-butyl hydroperoxide as initiator. Some other catalysts including metals such as $\mathrm{Co}, \mathrm{Fe}$, and $\mathrm{Mn}$ supported on $\gamma$-alumina, and supported pthalocyanines have also been reported to carry high activity and selectivity for the gas phase selective oxidation of $\mathrm{C}_{6} \mathrm{H}_{6}$ to $\mathrm{KA}$ oil, in the absence of solvents and reducing agents, under $1 \mathrm{~atm}$ of air pressure in the temperature range of $300{ }^{\circ} \mathrm{C}-400{ }^{\circ} \mathrm{C}[1]$.

Since reported for the first time in 2004, graphene has gained great attention in the scientific community [12]. Graphene, a two-dimensional material exhibits highly desirable physical characteristics such as a theoretical surface area of $2630 \mathrm{~m}^{2} / \mathrm{g}$ [13], high electronic and thermal conductivities [14], excellent mechanical properties [15], remarkable optical and electrical properties [16], and excellent chemical stability [17]. The interesting properties of graphene make it very attractive for possible applications in a variety of fields such as nanocomposites, nanoelectronics, batteries, supercapacitors, hydrogen storage, and sensors, etc. [18]. A number of different approaches have been developed for the synthesis of graphene sheets, however, the most efficient and suitable one is the reduction of graphite oxide (GO) to reduce graphene oxide in solution. This method of obtaining reduced graphene oxide is preferable because it is not only economical but also has a scalable, controlled, and reproducible synthetic nature [19]. The surfaces of GO have an abundance of functional groups which could be used as sites for anchoring nanoparticles. It is thus possible to utilize them as a support in the fabrication of hybrids of graphene and nanoparticles. Immobilizing various metal nanoparticles on graphene sheets can afford hybrid composites with admirable properties for a wide range of applications, including specifically catalytic applications [18].

It can be seen from the literature that graphene has a great significance as a heterogeneous catalyst support. Wang et al. [18] reported the catalytic performance of Pt nanoparticles supported on reduced graphene oxide for the electro-oxidation of methanol. Gold-nanoparticles and reduced graphene oxide composite has been reported for the efficient oxidation of benzyl alcohol [20]. Shouheng et al. [21] supported $\mathrm{Ni} / \mathrm{Pd}$ core/shell nanoparticles on graphene and used the sample as a catalyst in Suzuki-Miyaura cross-coupling reactions. The catalyst was found to be highly stable and efficient, and it provided a high percent conversion. Our group previously reported linear amino acids covalently immobilized on graphene sheet as catalysts for asymmetric aldol reactions between cyclohexanone and various aldehydes. The reactions were found to exhibit high yields as well as excellent ee values [22].

The application of Pt-Sn supported on carbon for the oxidation of ethanol by Tseng et al. [23] and of graphene as a support for various metals in heterogeneous catalysis inspired us to prepare $\mathrm{Pt}-\mathrm{Sn} /$ reduced graphene oxide composite and evaluate its catalytic performance for the selective oxidation of cyclohexane, which is a hydrocarbon and hence very inert to oxidation. To the best of our knowledge, the use of Pt-Sn/rGO as a catalyst for the liquid phase aerobic oxidation of cyclohexane to cyclohexanone and cyclohexanol has not been previously investigated. This paper describes our study on the catalytic efficiency of Pt-Sn/rGO to selectively oxidize liquid $\mathrm{C}_{6} \mathrm{H}_{6}$ to cyclohexanone and cyclohexanol by molecular oxygen, under mild reaction conditions. 


\section{Results and Discussion}

\subsection{Characterization of the Catalyst}

Figure 1a shows the SEM image of rGO, exhibiting a smooth lamellar structure. Figure $1 \mathrm{~b}$ through Figure 1e present the SEM images of Pt-Sn/rGO at different magnifications. These images clearly reveal a high yield of Pt-Sn in the form of well-dispersed tiny spheres anchored to the surface of rGO sheets. The average size of the rGO sheet is $<20 \mu \mathrm{m}$, thickness is $4-20 \mathrm{~nm}$ with $<30$ layers. The size of $\mathrm{Pt}-\mathrm{Sn}$ nanospheres is estimated by the intercept approach to be about $60-85 \mathrm{~nm}$. EDX spectrum show clear peaks for $\mathrm{Pt}$ and $\mathrm{Sn}$ in the sample. From the EDX analysis, the sample is found to contain $\mathrm{Pt}$ and Sn about 0.173 and $8.088 \mathrm{wt} \%$, respectively. The calculated amounts of $\mathrm{Pt}$ and $\mathrm{Sn}$ in the sample as based on the stoichiometric calculations are $0.144 \pm 0.029$ and $7.07 \pm 1.01 \mathrm{wt} \%$, respectively. It is quite evident that there is a reasonable agreement between the theoretical calculations and experimental results of the amounts of the metals on the support. Figure 2 shows the XRD patterns of the reduced graphene sheet and Pt-Sn decorated reduced graphene sheet. The diffraction peaks corresponding to Pt were observed at $2 \theta=39.8^{\circ}$ and $67.5^{\circ}$, while peaks for Sn appeared at $2 \theta=33.8^{\circ}$ and $51.3^{\circ}$, respectively as reported in the literature [23]. The broad peak for reduced graphene sheet appear was observed at $2 \theta=25^{\circ}$. Furthermore, no crystalline impurities were observed.
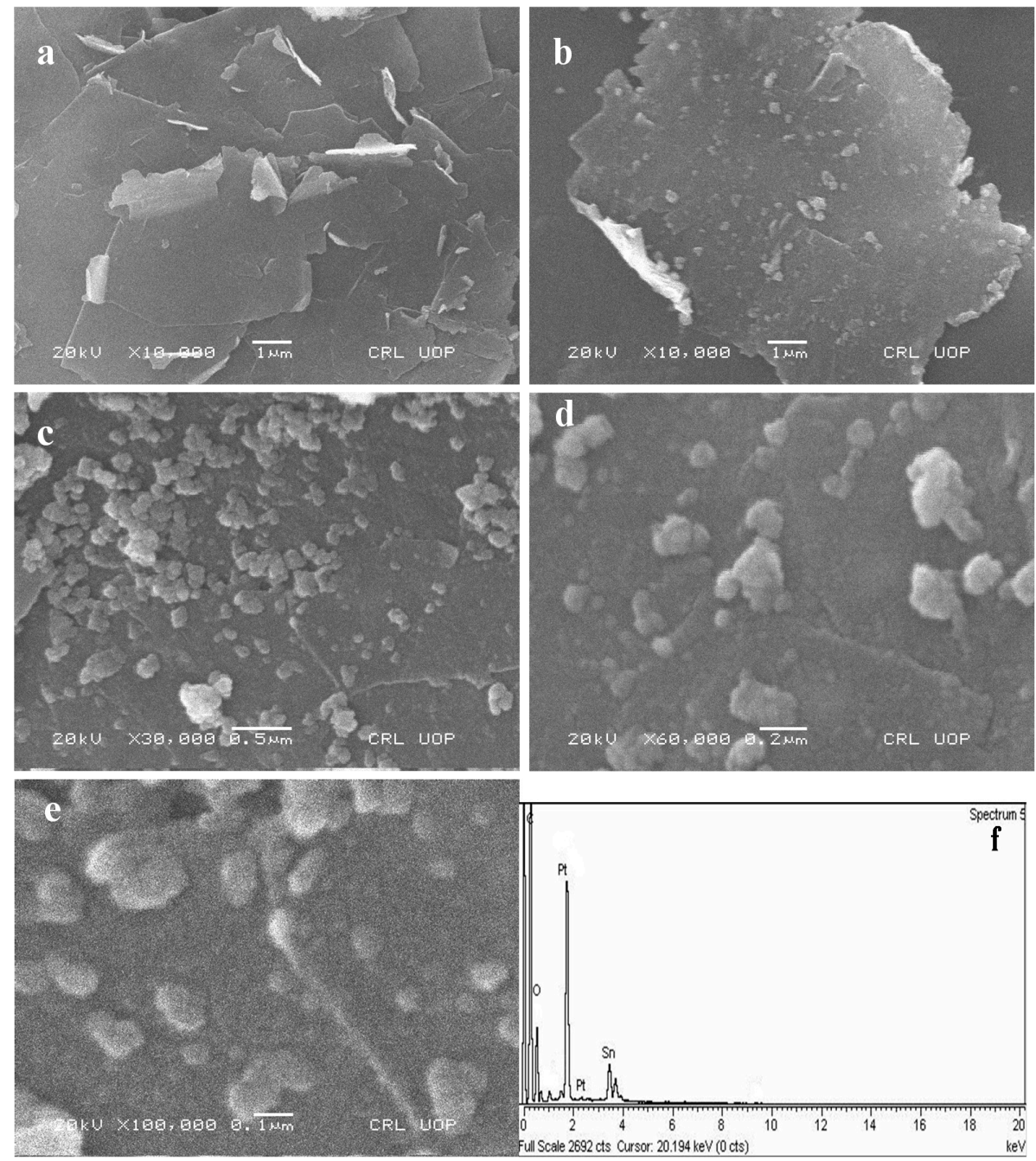

Figure 1. SEM images of (a) reduced graphene sheet, (b-e) Pt-Sn decorated reduced graphene sheet and (f) EDX of the Pt-Sn decorated reduced graphene sheet. 


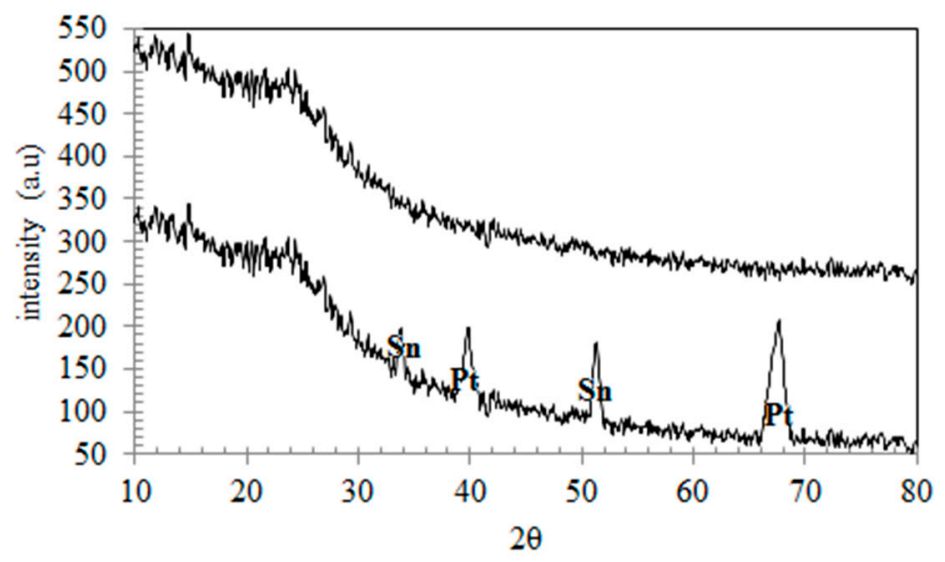

Figure 2. XRD patterns of reduced graphene sheet and Pt-Sn decorated reduced graphene sheet.

To discuss the nature of bond between the metallic spheres and the support, we resort to reports in literature. Li et al. [24] argued that rGO bears defects which include defect carbons with dangling bonds of the $s p^{2}$ type, developed as a result of the conversion of GO to its reduced form. These defect sites provide an effective mean of chemically adhering metals to the rGO. The same argument for the bonding of metal to the reduced grapheme has been made by Chen et al. [19]. This led us to assert that in our case, like in many others as reported in literature, the Pt-Sn nanospheres are anchored by true chemical bond to the rGO.

\subsection{Oxidation of Cyclohexane: Effect of Reaction Conditions}

The reaction was monitored periodically for about $12 \mathrm{~h}$ under a temperature of $343 \mathrm{~K}, 760$ Torr $\mathrm{pO}_{2}, 50 \mathrm{mg}$ of catalyst, and $10 \mathrm{~mL}$ of cyclohexane. Figure 3 presents data obtained for this part of the study in the form of the rate of the reaction as a function of time span of the reaction. The rate was calculated as the number of moles of the target products formed per gram of the catalyst per hour, which is thus an indirect measure of the selectivity to the desired products. It can be seen in the Figure 3 that the selectivity raises very rapidly as the time span of the reaction prolongs, until a maximum is reached in about $3 \mathrm{~h}$. In the last $9 \mathrm{~h}$, a progressive decrease in the selectivity is observed, showing the over-oxidation of the target.

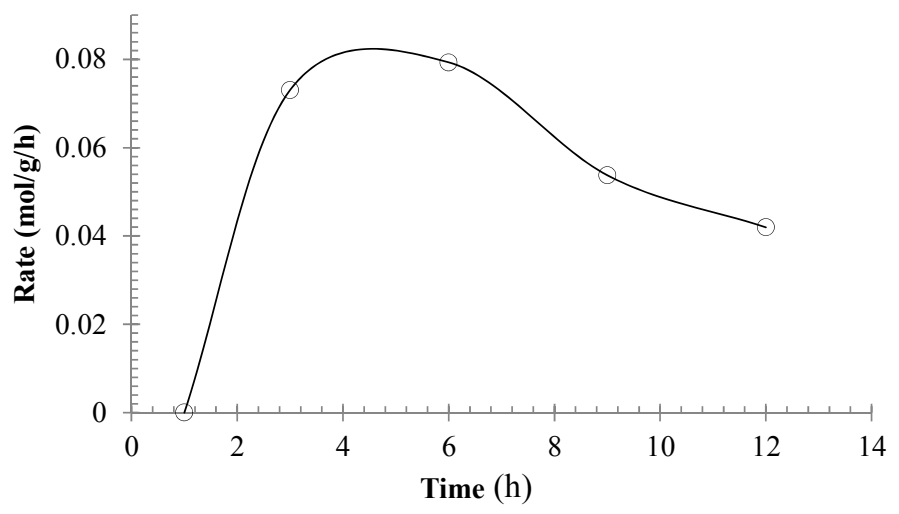

Figure 3. Time profile study of Pt-Sn/rGO sheet catalyzed liquid phase oxidation of cyclohexane to KA oil.

The effect of temperature was investigated in the range of $313-343 \mathrm{~K}$ by running the reaction under conditions; time: $3 \mathrm{~h}, \mathrm{pO}_{2}: 760$ Torr, catalyst: $50 \mathrm{mg}$, and $\mathrm{C}_{6} \mathrm{H}_{6}: 10 \mathrm{~mL}$. A linear relation was found to exist between conversion and temperature so that $343 \mathrm{~K}$ was chosen to be the optimal temperature for the reaction. Figure 4 shows the Arrhenius plot for the temperature study of the reaction. From the 
plot, the activation energy of the reaction is calculated to be $58.1 \mathrm{~kJ} \cdot \mathrm{mol}^{-1}$. The activation energy value of the reaction suggests that the catalytic reaction is kinetically controlled.

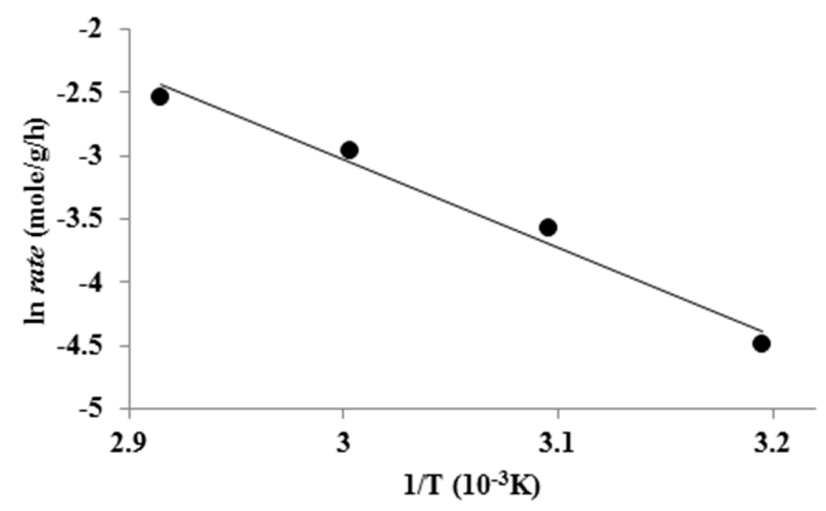

Figure 4. Arrhenius plot for the oxidation of cyclohexane to KA oil catalyzed by Pt-Sn/rGO sheet.

The study of the effect of the $\mathrm{pO}_{2}$ on the reaction under conditions, viz, temperature: $343 \mathrm{~K}$, time: $3 \mathrm{~h}$, catalyst: $50 \mathrm{mg}$, and cyclohexane: $10 \mathrm{~mL}$ showed that $\mathrm{pO}_{2}$ exerted a positive influence on the conversion of the substrate up to about 550 Torr. Above 550 Torr, no effect of the $\mathrm{pO}_{2}$ on conversion was observed. The data is recorded in Figure 5 in the form of rate vs $\mathrm{pO}_{2}$ plot which shows a plateau above 550 Torr. This might be due to the saturation of the surface with oxygen so that it is unable to accommodate additional oxygen resulting from an increase in the $\mathrm{pO}_{2}$.

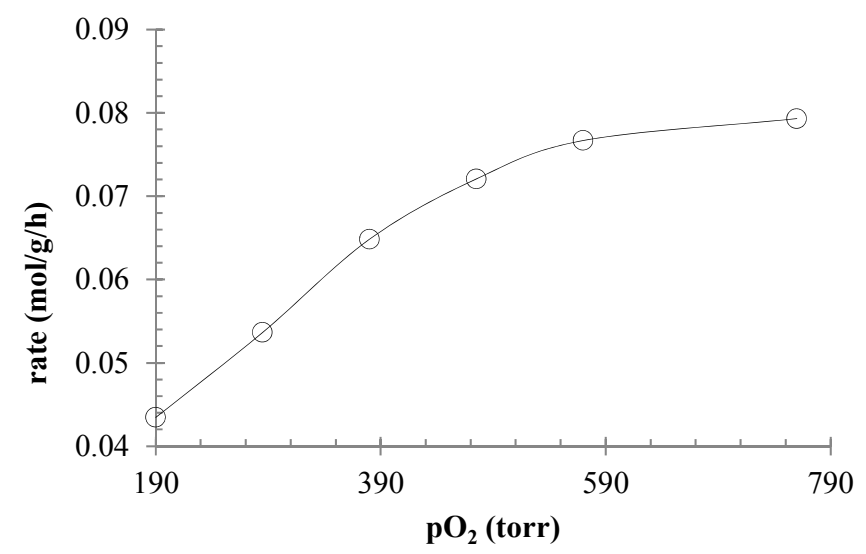

Figure 5. Effect of partial pressure of oxygen on the rate of liquid phase oxidation of cyclohexane catalyzed by Pt-Sn/rGO sheet.

The effect of stirring speed on the reaction was also included in the study. For the reaction under conditions as optimized thus far, the stirring speed when varied revealed that an increase in the stirring rate could enhance conversion only up to $580 \mathrm{rpm}$. At all values of stirring rate above $580 \mathrm{rpm}$, the conversion remained unchanged. This also suggests a kinetically controlled nature of the reaction. Because, were the reaction diffusion controlled, the conversion would increase with stirring speed without reaching a limit.

\subsection{Kinetic Analysis of the Data}

The data obtained for the solvent free liquid phase oxidation of cyclohexane by oxygen over $\mathrm{Pt}-\mathrm{Sn} / \mathrm{rGO}$ as catalyst was evaluated using Freundlich, Temkin, and Langmuir adsorption isotherms.

According to the modified form of Freundlich adsorption isotherm keeping cyclohexane concentration constant, the rate equation is given as;

$$
\text { Rate }=k_{r} K_{O_{2}}\left[O_{2}\right] \frac{1}{n}
$$


where

$$
\begin{gathered}
K_{F}=k_{r} K_{O_{2}} \\
\text { Rate }=K_{F}\left[O_{2}\right]^{\frac{1}{n}}
\end{gathered}
$$

the constants $K_{F}$ and $\mathrm{n}$ are two different temperature dependent parameters, where $n$ is greater than one and $K_{F}$ is considered as adsorption binding constant.

Similarly, Temkin adsorption isotherm was tested for the experimental data by putting the data in the modified form of Temkin adsorption isotherm. By keeping the concentration of cyclohexane constant, the rate equation of the Temkin model assumes the form as:

$$
\text { Rate }=k_{r}\left(K_{1} \ln K_{2}\left[O_{2}\right]\right)
$$

However, a satisfactory fit of the data was not obtained with either of the modified Freundlich and Temkin isotherm models. Hence, both Freundlich and Temkin models were excluded.

According to the Langmuir Hinshelwood mechanism the rate can be expressed as:

$$
\text { Rate }=\frac{k_{r} K p_{\mathrm{O}_{2}}}{1+K p_{\mathrm{O}_{2}}}
$$

where $k$ is the adsorption equilibrium constant of oxygen and $k_{r}$ is the rate constant.

In the linear form, equation (5) becomes:

$$
\frac{1}{\text { Rate }}=\frac{1}{k_{r} K p_{\mathrm{O}_{2}}}+\frac{1}{K_{r}}
$$

It can be further modified as:

$$
\frac{p_{\mathrm{O}_{2}}}{\text { Rate }}=\frac{1}{k_{r} \mathrm{~K}}+\frac{p_{\mathrm{O}_{2}}}{k_{r}}
$$

The experimental data was fitted to equation (7) as presented in Figure 6, and a regression value of 0.9853 was obtained. Then the data was subjected to kinetic analysis using nonlinear square fit method, and the rates were calculated using the values of $k_{r}$ and $K$. The plots of the experimental and calculated rates are given in Figure 7 as the functions of $\mathrm{pO}_{2}$, showing an excellent mutual correlation. Thus to conclude kinetic analysis, L-H adsorption isotherm model explains the kinetics of the catalytic reaction.

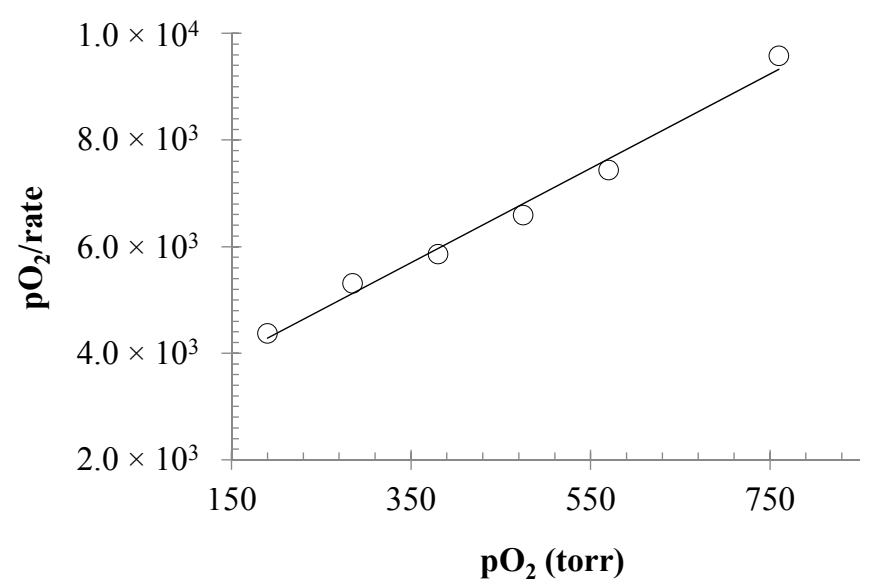

Figure 6. Plot of $\mathrm{pO}_{2} /$ rate vs $\mathrm{pO}_{2}$ according to linear form of the Langmuir-Hinshelwood model. 


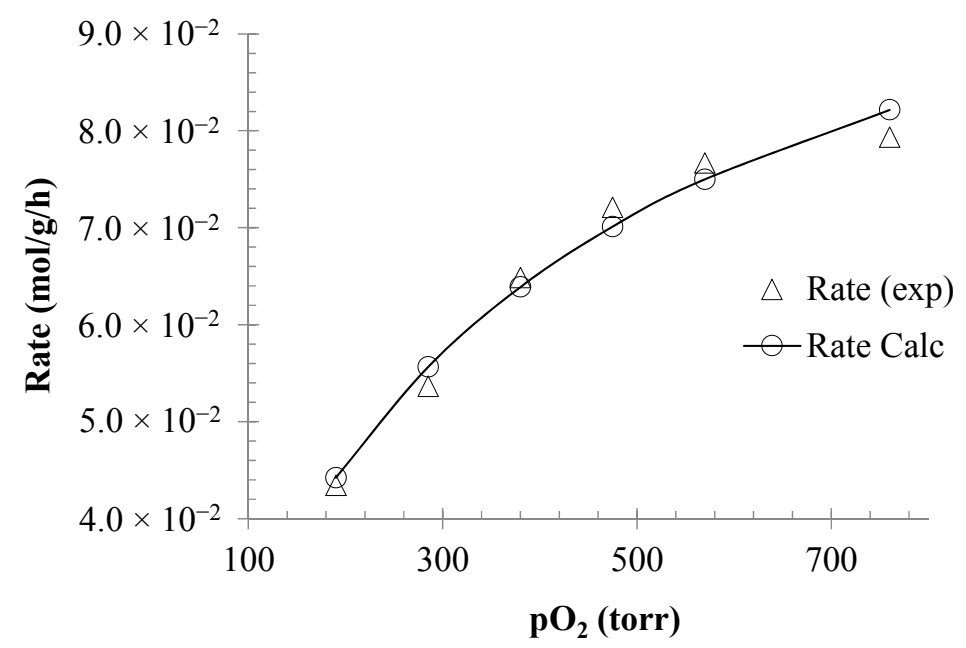

Figure 7. Plot of calculated and experimental rates vs. $\mathrm{pO}_{2}$ according to non-linear square fit (L-H model).

\section{Experimental Section}

\subsection{General}

The chemicals used in the present study were of high purity and research grade and were used without any further purification. Nitrogen and oxygen were supplied by BOC (Texila, Pakistan) and for their further purification specific filters (C.R.S.Inc.202268 \& C.R.S.Inc.202223) were used.

\subsection{Synthesis of Pt-Sn Supported on Graphene Oxide (Pt-Sn/rGO)}

Graphene oxide (GO) was synthesized from graphite powder using modified Hummer's method. To a mixture of $1 \mathrm{~g}$ of graphite and $0.5 \mathrm{~g}$ of sodium nitrate, $23 \mathrm{~mL}$ of conc. $\mathrm{H}_{2} \mathrm{SO}_{4}$ was added under constant stirring. After $1 \mathrm{~h}, 3 \mathrm{~g}$ of $\mathrm{KMnO}_{4}$ was added slowly while keeping the temperature less than $293 \mathrm{~K}$ to prevent overheating and explosion. The mixture was stirred at $308 \mathrm{~K}$ for $12 \mathrm{~h}$ and the resulting solution was diluted by adding $500 \mathrm{~mL}$ of water under vigorous stirring. To ensure the completion of reaction with $\mathrm{KMnO}_{4}$, the suspension was further treated with $30 \% \mathrm{H}_{2} \mathrm{O}_{2}$ solution ( $5 \mathrm{~mL}$ ). The resulting mixture was filtered and washed in turn with $\mathrm{HCl}$ and $\mathrm{H}_{2} \mathrm{O}$. The mixture was then filtered and dried to get graphene oxide. GO was then reduced to $\mathrm{GGO}$ by stirring with hydrazine monohydrate ( $1 \mu \mathrm{L}$ for $3 \mathrm{mg}$ of GO) at $353 \mathrm{~K}$ for $12 \mathrm{~h}$.

In the next step, $\mathrm{rGO}$ was treated with $500 \mathrm{~mL}$ solution of $\mathrm{SnCl}_{2}(11.3 \mathrm{~g})$ and $\mathrm{HCl}(13 \mathrm{~mL})$. The mixture was sonicated for $30 \mathrm{~min}$ and allow to age for $48 \mathrm{~h}$ at $25^{\circ} \mathrm{C}$. Then rGO was separated by centrifugation and decantation and first washed with double distilled water (DDW), and then with $\mathrm{N}$-hexane. Subsequently, the sample was treated with $500 \mathrm{~mL}$ solution of $\mathrm{PtCl}_{4}(0.25 \mathrm{~g})$ and $\mathrm{HCl}$ $(13 \mathrm{~mL})$ and the mixture was sonicated for $30 \mathrm{~min}$ at room temperature. The same procedure for separation and washing with DDW and $\mathrm{N}$-hexane, as mentioned earlier, was followed again.

\subsection{Characterization of the Catalyst}

$\mathrm{Pt}-\mathrm{Sn} / \mathrm{rGO}$ was characterized by modern techniques including scanning electron microscopy (SEM, JSM 5910, Jeol, Japan) and energy dispersive X-ray spectroscopy (EDX) of the sample were recorded on EDX detecters (INC200, Oxford, UK). The powder X-ray Diffraction spectrum was recorded on X-ray Diffractometer (XRD) Rigaku D/Max-II, Jeol, Japan.

\subsection{Catalytic Test}

In a typical catalytic test, under specified conditions of temperature, pressure of oxygen, and stirring speed, oxygen or a mixture of oxygen and nitrogen was bubbled through a suspension of 50 
mg of Pt-Sn/rGO in $10 \mathrm{~mL}$ of $\mathrm{C}_{6} \mathrm{H}_{6}$ while the suspension was stirred by a magnetic stirrer. The flow of gases was regulated by needle valves, and the temperature was maintained by a heating cord and monitored by a $K$ type thermocouple connected to a Digital Temperature Controller ( 55 rajah crescent, Singapore). The catalyst was recovered by simple filtration. The products were monitored by gravimetric method, Ultraviolet-visible spectrophotometer, and Gas Chromatography fitted with Flame Ionization Detector.

\section{Conclusions}

Pt-Sn/rGO sheets were prepared and characterized by SEM, EDX, and XRD. The catalytic potential of the sample was tapped for the solvent free liquid phase oxidation of cyclohexane to KA oil, under mild conditions of reaction. The reaction conditions were optimized as; Cyclohexane: $10 \mathrm{~mL}$, Catalyst: $50 \mathrm{mg}$, Temperature: $343 \mathrm{~K}_{,} \mathrm{pO}_{2}$ : 550 Torr, and Stirring speed: $580 \mathrm{rpm}$ and obtain $24.1 \%$ conversion and $90 \%$ selectivity. The sample was recoverable from the reaction mixture simply by filtration, and was found not to experience any appreciable loss in activity for the reaction during four successive runs. Kinetic analysis of the data revealed that the reaction follows the L-H model for non-competitive adsorption.

The study will be extended further to obtain an elaborate comparison of the activity and selectivity of Pt-Sn/GO sheets and Pt-Sn/rGO sheets.

Acknowledgments: The authors greatly acknowledge financial support from Higher Education Commission of Pakistan, Pakistan Science Foundation, and University of Malakand, Khyber Pakhtunkhwa, Pakistan.

Author Contributions: Mohammad Sadiq, principal investigator and supervisor; Khalid Saeed, prepared the catalyst; Saima Sadiq, preform catalytic activity of the catalyst, Muhammad Sohail Ahmad, characterized the catalyst; Muhammad Ali, write the article; Muhammad Abid Zia and Rahmat Ali, help in the research and writing.

Conflicts of Interest: The authors declare no conflict of interest.

\section{References}

1. Ebadi, A.; Safari, N.; Peyrovi, M.H. Aerobic oxidation of cyclohexane with $\gamma$-alumina supported metallophthalocyanines in the gas phase. Appl. Catal. A Gen. 2007, 321, 135-139. [CrossRef]

2. Chen, L.; Zhou, T.; Chen, L.; Ye, Y.; Qi, Z.; Freund, H.; Sundmacher, K. Selective oxidation of cyclohexanol to cyclohexanone in the ionic liquid 1-octyl-3-methylimidazolium chloride. Chem. Commun. 2011, 47, 9354-9356. [CrossRef] [PubMed]

3. Salavati-Niasari, M.; Zamani, E.; Ganjali, M.R.; Norouzi, P. Synthesis, characterization and liquid phase oxidation of cyclohexanol using tert-butylhydroperoxide over host (zeolite-Y)/guest (copper (II) complexes of 12-and 13-membered diaza dioxa Schiff-base macrocyclic ligand) nanocomposite materials (HGNM). J. Mol. Catal. A Chem. 2007, 261, 196-201. [CrossRef]

4. Yi, Q.; Zhang, J.; Huang, W.; Liu, X. Electrocatalytic oxidation of cyclohexanol on a nickel oxyhydroxide modified nickel electrode in alkaline solutions. Catal. Commun. 2007, 8, 1017-1022. [CrossRef]

5. Sakthivel, A.; Selvam, P. Mesoporous (Cr) MCM-41: A mild and efficient heterogeneous catalyst for selective oxidation of cyclohexane. J. Catal. 2002, 211, 134-143. [CrossRef]

6. Conte, M.; Liu, X.; Murphy, D.M.; Whiston, K.; Hutchings, G.J. Cyclohexane oxidation using Au/MgO: An investigation of the reaction mechanism. Phys. Chem. Chem. Phys. 2012, 14, 16279-16285. [CrossRef] [PubMed]

7. Yu, H.; Peng, F.; Tan, J.; Hu, X.; Wang, H.; Yang, J.; Zheng, W. Selective catalysis of the aerobic oxidation of cyclohexane in the liquid phase by carbon nanotubes. Angew. Chem. Int. Ed. Engl. 2011, 50, 3978-3982. [CrossRef] [PubMed]

8. Maksimchuk, N.V.; Kovalenko, K.A.; Fedin, V.P.; Kholdeeva, O.A. Cyclohexane selective oxidation over metal-organic frameworks of MIL-101 family: Superior catalytic activity and selectivity. Chem. Commun. 2012, 48, 6812-6814. [CrossRef] [PubMed]

9. Schuchardt, U.; Pereira, R.; Krähembühl, C.E.; Rufo, M.; Buffon, R. Synergistic effect of iron and copper oxides supported on silica in the room temperature oxidation of cyclohexane. Appl. Catal. A Gen. 1995, 131, 135-141. [CrossRef] 
10. Zhou, L.; Xu, J.; Miao, H.; Wang, F.; Li, X. Catalytic oxidation of cyclohexane to cyclohexanol and cyclohexanone over $\mathrm{Co}_{3} \mathrm{O}_{4}$ nanocrystals with molecular oxygen. Appl. Catal. A Gen. 2005, 292, 223-228. [CrossRef]

11. Da Cruz, R.S.; Silva, J.M.D.S.; Arnold, U.; Schuchardt, U. Catalytic activity and stability of a chromium containing silicate in liquid phase cyclohexane oxidation. J. Mol. Catal. A Chem. 2001, 171, 251-257. [CrossRef]

12. Huang, H.; Sun, D.; Wang, X. Pt-Co alloy nanoparticles supported on graphene nanosheets with high performance for methanol oxidation. Chin. Sci. Bull. 2012, 57, 3071-3079. [CrossRef]

13. Bolotin, K.I.; Sikes, K.J.; Jiang, Z.; Klima, M.; Fudenberg, G.; Hone, J.; Stormer, H.L. Ultrahigh electron mobility in suspended graphene. Solid State Commun. 2008, 146, 351-355. [CrossRef]

14. Marinkas, A.; Arena, F.; Mitzel, J.; Prinz, G.M.; Heinzel, A.; Peinecke, V.; Natter, H. Graphene as catalyst support: The influences of carbon additives and catalyst preparation methods on the performance of PEM fuel cells. Carbon 2013, 58, 139-150. [CrossRef]

15. Lee, C.; Wei, X.; Kysar, J.W.; Hone, J. Measurement of the elastic properties and intrinsic strength of monolayer graphene. Science 2008, 321, 385-388. [CrossRef] [PubMed]

16. Ghosh, S.; Calizo, I.; Teweldebrhan, D.; Pokatilov, E.P.; Nika, D.L.; Balandin, A.A.; Lau, C.N. Extremely high thermal conductivity of graphene: Prospects for thermal management applications in nanoelectronic circuits. Appl. Phys. Lett. 2008, 92, 151911. [CrossRef]

17. Metin, Ö.; Kayhan, E.; Özkar, S.; Schneider, J.J. Palladium nanoparticles supported on chemically derived graphene: An efficient and reusable catalyst for the dehydrogenation of ammonia borane. Int. J. Hydrog. Energy 2012, 37, 8161-8169. [CrossRef]

18. Li, Y.; Gao, W.; Ci, L.; Wang, C.; Ajayan, P.M. Catalytic performance of Pt nanoparticles on reduced graphene oxide for methanol electro-oxidation. Carbon 2010, 48, 1124-1130. [CrossRef]

19. Hsu, K.C.; Chen, D.H. Green synthesis and synergistic catalytic effect of Ag/reduced graphene oxide nanocomposite. Nanoscale Res. Lett. 2014, 9, 1-10. [CrossRef] [PubMed]

20. Yu, X.; Huo, Y.; Yang, J.; Chang, S.; Ma, Y.; Huang, W. Reduced graphene oxide supported Au nanoparticles as an efficient catalyst for aerobic oxidation of benzyl alcohol. Appl. Surf. Sci. 2013, 280, 450-455. [CrossRef]

21. Metin, Ö.; Ho, S.F.; Alp, C.; Can, H.; Mankin, M.N.; Gültekin, M.S.; Sun, S. Ni/Pd core/shell nanoparticles supported on graphene as a highly active and reusable catalyst for Suzuki-Miyaura cross-coupling reaction. Nano Res. 2013, 6, 10-18. [CrossRef]

22. Sadiq, M.; Aman, R.; Saeed, K.; Ahmad, M.S.; Zia, M.A. Green and sustainable heterogeneous organo-catalyst for asymmetric aldol reactions. Mod. Res. Catal. 2015, 4, 43. [CrossRef]

23. Su, B.J.; Wang, K.W.; Tseng, C.J.; Wang, C.H.; Hsueh, Y.J. Synthesis and catalytic property of PtSn/C toward the ethanol oxidation reaction. Int. J. Electrochem. Sci. 2012, 7, 5246-5255.

24. Zhang, W.; Li, Y.; Zeng, X.; Peng, S. Synergetic effect of metal nickel and graphene as a cocatalyst for enhanced photocatalytic hydrogen evolution via dye sensitization. Sci. Rep. 2015, 5. [CrossRef] [PubMed]

(C) 2016 by the authors; licensee MDPI, Basel, Switzerland. This article is an open access article distributed under the terms and conditions of the Creative Commons by Attribution (CC-BY) license (http://creativecommons.org/licenses/by/4.0/). 